CIUDAD Y TERRITORIO

ESTUDIOS TERRITORIALES

ISSN(P): 2697-231X; ISSN(E): 2697-2328

Vol. LIII, N.ำ Monográfico 2021

Págs. 119-138

https://doi.org/10.37230/CyTET.2021.M21.07

CC BY-NC-ND

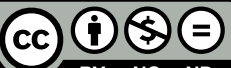

\title{
Efectos del abandono de las políticas públicas de vivienda en barrios populares y multiculturales
}

\author{
Daniel SORANDO-ORTIN ${ }^{(1)}$ \\ Chabier GIMENO-MONTERDE ${ }^{(2)}$
}

(1) Profesor Ayudante Doctor, GISMAT-Instituto TRANSOC. UCM (2) Profesor Ayudante Doctor, Universidad de Zaragoza

RESUMEN: Los barrios periféricos del desarrollismo franquista atraviesan procesos de diversificación y precarización similares, acogiendo hoy a una población multicultural y con posiciones de clase populares. El estudio cuantitativo de los cambios sociodemográficos en dos barrios de Zaragoza y Madrid es complementado, mediante una aproximación cualitativa, con el análisis de las estrategias vecinales, tanto colectivas como individuales. Estas se despliegan, con mayor o menor éxito, ante la ausencia de unas políticas públicas de vivienda que frenen el deterioro urbanístico y social de estos territorios. Concluimos que los contextos políticos locales, tanto institucionales como asociativos, propician diferentes ritmos en la evolución de la precarización de la vivienda y sus habitantes. En ambos casos, estas fases convergen en escenarios de reperiferización.

PALABRAS CLAVE: Precarización; Vivienda; Multiculturalidad; Redes; Fragmentación.

\section{Effects of the abandonment of public housing policies in popular and multicultural neighbourhoods}

ABSTRACT: The peripheral neighborhoods of Francoist "desarrollismo" period are going through similar diversification and precarization processes. Nowadays, they are the place of residence of a multicultural population with popular class positions. The quantitative study of the sociodemographic changes in two

Recibido: 08.07.2020; Revisado: 26.11.2020.

Correo electrónico: dsorando@ucm.es; N. ORCID: https://orcid.org/0000-0003-0882-527X

Correo electrónico: chabierg@unizar.es; N. ${ }^{\circ}$ ORCID: https://orcid.org/0000-0002-5746-1372

Los autores agradecen los comentarios y sugerencias realizados por los evaluadores anónimos, que han contribuido a mejorar y enriquecer el manuscrito original.

Nuestro agradecimiento a Pilar Aguerri y Eloísa García, de la Sociedad Municipal Zaragoza Vivienda, por los contactos de residentes en Las Fuentes; y a Saray Lorente, estudiante de Trabajo Social en la Universidad de Zaragoza, por su trabajo de campo en esta ciudad. También queremos agradecer su trabajo a Ivo Jurado, Sara Porras y Triksia Salvador por su trabajo de campo en Abrantes. 
neighborhoods of Zaragoza and Madrid is complemented, through a qualitative approach, with the analysis of neighborhood strategies, both collective and individual. These strategies are deployed with diverse success, and in the absence of public housing policies that could stop the urban and social deterioration of these territories. We conclude that local political contexts, both institutional and associative, foster different rhythms in the evolution of the precariousness of housing and its inhabitants. In both cases, these stages converge in scenarios of re-peripheralization.

Keywords: Precarization; Housing; Multiculturalism; Networks; Fragmentation.

\section{Introducción ${ }^{1}$}

os barrios edificados durante las últimas décadas de la dictadura militar en España se conformaron con una posición social homogénea (FERNÁNDEZ, 2007). Sin embargo, el ciclo de especulación inmobiliaria de comienzos de este siglo, los cambios demográficos (envejecimiento y migraciones internacionales) y la debilidad de la política de vivienda pública dirigida a las clases populares han provocado una diversificación de estos territorios, antaño periféricos (LóPEZ \& RODRÍGUEZ, 2010).

Como nuevos barrios populares multiculturales, en este artículo se presentan los casos de Abrantes (Madrid) y Las Fuentes (Zaragoza). En ellos se han estudiado los efectos del urbanismo neoliberal, que ha abandonado progresivamente las políticas de rehabilitación y de promoción del acceso a la vivienda para los colectivos más precarizados. Con un enfoque cuantitativo, se caracterizan los cambios demográficos a la vez que se abordan cualitativamente las estrategias colectivas (o su ausencia) y la percepción sobre la evolución socio urbanística por parte de habitantes y profesionales. A partir de esa combinación metodológica, se responde a la pregunta de investigación, ¿qué factores condicionan las estrategias de los colectivos precarizados para acceder a la vivienda o mejorar la situación de esta en este tipo de barrios populares? En primer lugar, presentamos brevemente la literatura que enmarca esta pregunta. En segundo lugar, caracterizamos la evolución de estos barrios. En tercer lugar, abordamos los discursos sobre los cambios sociodemográficos, los servicios y la pertenencia al territorio, la situación de la vivienda y las percepciones sobre las acciones públicas y privadas en torno a esta. Por último, planteamos las implicaciones que este escenario tiene para las políticas públicas y la movilización social de la nueva década.

\footnotetext{
1 Este artículo es resultado del proyecto de I+D+i "Influencia de los cambios en los regímenes de producción y acceso a la vivienda sobre la restructuración social de las grandes ciudades españolas" (CSO2017-83968-R). Programa Estatal
}

\section{Marco teórico}

A diferencia de lo ocurrido en los países europeos de industrialización temprana, la regulación del crecimiento y la transformación de las ciudades españolas nunca ha considerado el problema de la vivienda popular como un asunto central. Por el contrario, la legislación urbanística española ha subordinado la satisfacción de las necesidades de las clases populares a las expectativas de rendimiento privado del mercado del suelo. Una consecuencia de la combinación de esta tradición urbanística con el despliegue de la política de vivienda franquista fue la formación, en plena emigración rural a mediados del siglo $X X$, de grandes cinturones de chabolas y barracas autoconstruidas en la periferia de las principales ciudades españolas. La emergencia de estos asentamientos informales se añadía al déficit de viviendas acumulado durante las décadas anteriores (BETRÁN, 2005; LEAL, 2005).

En este escenario, la dictadura militar promovió el acceso formal a la vivienda en propiedad de los hogares que, o bien residían en los asentamientos informales, o bien carecían de medios económicos para acceder al mercado de la vivienda libre, dentro de una estrategia política y económica con efectos a largo plazo. Para ello, y entre otras herramientas, el Estado franquista combinó la construcción pública de viviendas (al comienzo del desarrollismo) con la subvención del acceso a la propiedad (particularmente a partir de los años setenta), ya fuera con ayudas a los promotores privados $O$ a los compradores (BETRÁN, 2002; SAMBRICIO, 2004). En ambos casos se dio lugar a conjuntos de vivienda periférica y de insuficiente calidad, mediante operaciones fragmentadas que no contaban con infraestructuras ni equipamientos (FERNÁNDEZ, 2003). Si bien buena parte de los problemas dotacionales fueron abordados

de Investigación, Desarrollo e Innovación Orientada a los Retos de la Sociedad, convocatoria de 2017. MINISTERIO DE CIENCIA, INNOVACIÓN Y UNIVERSIDADES. 
por los primeros ayuntamientos democráticos, la generalizada penalización de la rehabilitación a favor de la nueva construcción se ha mantenido después de 1975 (BETRÁN, 2002). Como consecuencia, los barrios periféricos del desarrollismo franquista se encuentran a comienzo de siglo XXI entre aquellos con mayor tasa de infravivienda (CORTÉs, 2008) e inadecuación de sus tipologías a los estándares contemporáneos (GARCíA, 2015).

No obstante, la trayectoria de este tipo de barrios no ha sido homogénea. Así, en algunos casos el poder político colectivo de los residentes logró mejoras en sus barrios, de manera que su composición social ha permanecido homogénea. En cambio, en el resto de los barrios del desarrollismo, donde han permanecido condiciones residenciales deterioradas, se observa un proceso muy distinto (UCEDA \& al., 2018). Dado su menor valor en el mercado, las viviendas de este segundo tipo de barrios han sido habitadas por los sectores sociales (inmigrantes y jóvenes de rentas bajas) cuya (in)solvencia económica sólo les permite residir en estos espacios. Esta necesidad permitió el relativo enriquecimiento de ciertas fracciones de las clases trabajadoras tradicionales, las cuales han dejado estos barrios para dirigirse hacia nuevos desarrollos suburbanos durante la primera década del siglo XXI (NEL·LO, 2004; LóPEZ \& RodrígueZ, 2010; SoRANDO \& UCEDA, 2018), especialmente en el caso de los hijos de las primeras generaciones que se asentaron en estos barrios, procedentes del ámbito rural (PAREJA -EASTAWAY \& al., 2003).

El resultado es la generación de periferias interiores, entendidas estas como el conjunto de espacios degradados que se ubican dentro de un barrio, correspondientes a zonas de una antigua periferia urbana que quedó congelada en el tiempo, a la que el crecimiento de la ciudad atravesó en su recorrido, dejándola olvidada en su desarrollo (KÁPSTEIN, 2010). En su modelo de ciudad partida, MARCUSE \& VAN KEMPEN (2000) identifican a estas periferias interiores como un subtipo de la tenement city, aquel compuesto por vivienda construida en las primeras décadas tras la Segunda Guerra Mundial, en el anillo externo a las áreas de rehabilitación, deterioradas por el abandono de viviendas construidas con malos materiales, donde las clases medias de ingresos humildes son reemplazadas por las nuevas clases precarias.

Además, estas dinámicas encuentran sus condiciones de posibilidad en el abandono de la política de vivienda social en España, así como de las medidas dirigidas a promover la mezcla social, a diferencia de lo ocurrido en los países del Norte de Europa (ANDERSSON \& MUSTERD, 2005; Housing EUROPE, 2019). El resultado es la formación de barrios que acogen a posiciones sociales comunes que, en cambio, proceden de trayectorias muy diversas, lo cual plantea interrogantes sobre el establecimiento de redes comunitarias de apoyo mutuo (SKIFTER, 2003; MARTíN-CRIADO, 2012). Frente a dichas dinámicas y tras la crisis posterior a 2008, diferentes iniciativas a escala local han mostrado que, a pesar de las condiciones objetivas desfavorables de un barrio, se articulan nuevas formas de solidaridad que promueven y dibujan salidas colectivas a la crisis (REVILLA \& al, 2017). En estos casos los diferentes grupos con intereses en el barrio se organizan para mejorar el destino de su vida social a través de diversas redes de apoyo mutuo (DESMOND, 2012; HERRERAPINEDA \& IBÁÑEZ, 2016).

\section{Metodología}

El material empírico empleado para analizar el objeto de estudio de esta investigación se basa en una aproximación a los barrios en dos etapas. En primer lugar, ambos barrios han sido descritos mediante datos secundarios procedentes de fuentes estadísticas oficiales. Asimismo, diferentes documentos de diagnóstico de los barrios, tanto públicos como del tercer sector, han sido utilizados para completar su análisis sociodemográfico y residencial. Una vez situados los barrios en su entorno urbano, la segunda etapa de investigación ha recogido las percepciones de los diferentes agentes individuales y colectivos de cada uno de estos territorios. La principal estrategia ha consistido en la elaboración, transcripción y análisis de contenido de una serie de entrevistas abiertas con los siguientes perfiles:

A. Actores colectivos: asociaciones de vecinos clásicas (protagonistas de las movilizaciones durante la transición) y posteriores al movimiento $15 M$, surgido en 2011.

B. Informantes clave: trabajadores en los servicios sociales, sanitarios y educativos; en el tercer sector; y participantes en foros comunitarios.

C. Residentes: madres en hogares monomarentales, jóvenes precarizados, migrantes nacidos en el extranjero, mayores de 65 años.

En total, se han realizado 17 entrevistas, de las cuales 10 han sido desarrolladas en Abrantes (Madrid) y 7 en Las Fuentes (Zaragoza), con una distribución de perfiles que se recoge en la FIG. 1. 
El guión de estas entrevistas recogía una serie de temas (necesidades sociales y residenciales, estrategias cotidianas, identidad y organización colectiva), si bien su desarrollo perseguía "la producción de un discurso conversacional, continuo y con una cierta línea argumental, no fragmentada, segmentada, precodificado y cerrado por un cuestionario previo" (ALONSO, 2007: 228).

\begin{tabular}{lcc}
\hline & Abrantes & Las Fuentes \\
\hline Informante Clave & 4 & 2 \\
\hline Asociación Clásica & 1 & 1 \\
\hline Asociación post 15M & 1 & - \\
\hline Joven precarizado & 1 & - \\
\hline Joven precarizada & 1 & 1 \\
\hline Hombre migrante & 1 & 1 \\
\hline Mujer migrante & - & 1 \\
\hline Hogar monomarental & 1 & 1 \\
\hline $\begin{array}{l}\text { Flg. 1/ Distribución de los perfiles entrevistados } \\
\text { según barrio. }\end{array}$
\end{tabular}

Fuente: elaboración propia.

En el caso de Las Fuentes, las entrevistas han sido complementadas con la elaboración de un grupo focal en torno a las relaciones sociales entre grupos de residentes en el barrio ${ }^{2}$. En este grupo participaron 7 mujeres y 4 hombres, habitantes y actores clave del territorio (profesionales de entidades públicas y privadas) con participación en diversos ámbitos (deportes, tercera edad, salud, asociaciones de migrantes, infancia y juventud, educación, asociaciones de vecinos, empleo y servicios sociales). Estos perfiles fueron buscados intencionalmente para lograr una representación equitativa por género, origen étnico y grupo de edad. Dicho grupo fue celebrado en 2018, así como las entrevistas que se realizaron en Abrantes. Las entrevistas en Las Fuentes, en cambio, se desarrollaron entre 2019 y 2020.

En ambos casos se realizó un análisis de dos fases del material discursivo. En primer lugar, se analizaron "verticalmente" (un audio o unidad de análisis a la vez), para identificar unidades de significado aproximado. En segundo lugar, se codificaron "horizontalmente" (el conjunto de las grabaciones), generando categorías analíticas y palabras clave más amplias, comunes a los dos

\footnotetext{
${ }^{2}$ En el marco del proyecto de I+D+i "Convivencia y barrios multiculturales: conflicto y cohesión social en una España en crisis" (CSO2014-54487-R), dirigido por Pilar Monreal.
}

territorios. Estas nos permiten plantear diversos conglomerados de discurso a través de procesos de asociación y disociación (JøRGENSEN \& PHILLIPS, 2002), así como temas emergentes, que se presentan en los resultados.

\section{Contextualización de los barrios}

\subsection{Abrantes (Madrid)}

El barrio de Abrantes (30.748 habitantes en 2019, según el Padrón municipal) es parte del distrito de Carabanchel (253.040 habitantes, INSTITUTO NACIONAL DE Estadística, 2020) y se localiza en su parte oriental. Se trata de un barrio con una densidad de habitantes de $190,3 \mathrm{Hab} / \mathrm{Has}$, muy por encima de los 53,3 $\mathrm{Hab} / \mathrm{Has}$ de media de la ciudad de Madrid. Si bien el origen del barrio está en la primera mitad del siglo XX, su configuración actual es el resultado de las necesidades de vivienda ligadas a la combinación de la intensa destrucción de viviendas en Carabanchel durante la Guerra Civil $y$, principalmente, de la intensa llegada a Madrid de migrantes rurales a partir de 1950. En el caso concreto del territorio de Abrantes, se producen asentamientos de casas bajas y grandes núcleos chabolistas, entre ellos el de Pan Bendito, al sur del barrio.

Entre 1950 y 1970, y con el fin de dar respuesta a la inadecuación de estas viviendas, las antiguas casas bajas fueron reemplazadas por bloques de vivienda colectiva, y se promovió la construcción de un importante número de promociones de vivienda protegida (DíEZ, 2015). Estas actuaciones públicas incluyen la colonia de San Vicente de Paúl (entre 1950 y 1959) y la Unidad Vecinal de Absorción de Pan Bendito (1963). Junto con estas promociones públicas, las Colonias Velázquez (década de 1950) y la Colonia Zoyme (1964) son conjuntos de vivienda privada acogida a subvención pública (ver FIG.2). Estas actuaciones definen Abrantes como un barrio característico del desarrollismo franquista, dado que el $56,4 \%$ de sus viviendas fue construido entre 1950 y 1970 , a diferencia del $37,2 \%$ de la ciudad de Madrid, según el Censo de 2011 (INSTITUTO NACIONAL DE EsTAdísticA, 2013).

Las precarias condiciones residenciales y urbanísticas de estas actuaciones dieron lugar a intervenciones posteriores, como la remodelación

Convocatoria 2014 "Retos de Investigación". Ministerio de Economía y Competitividad. 


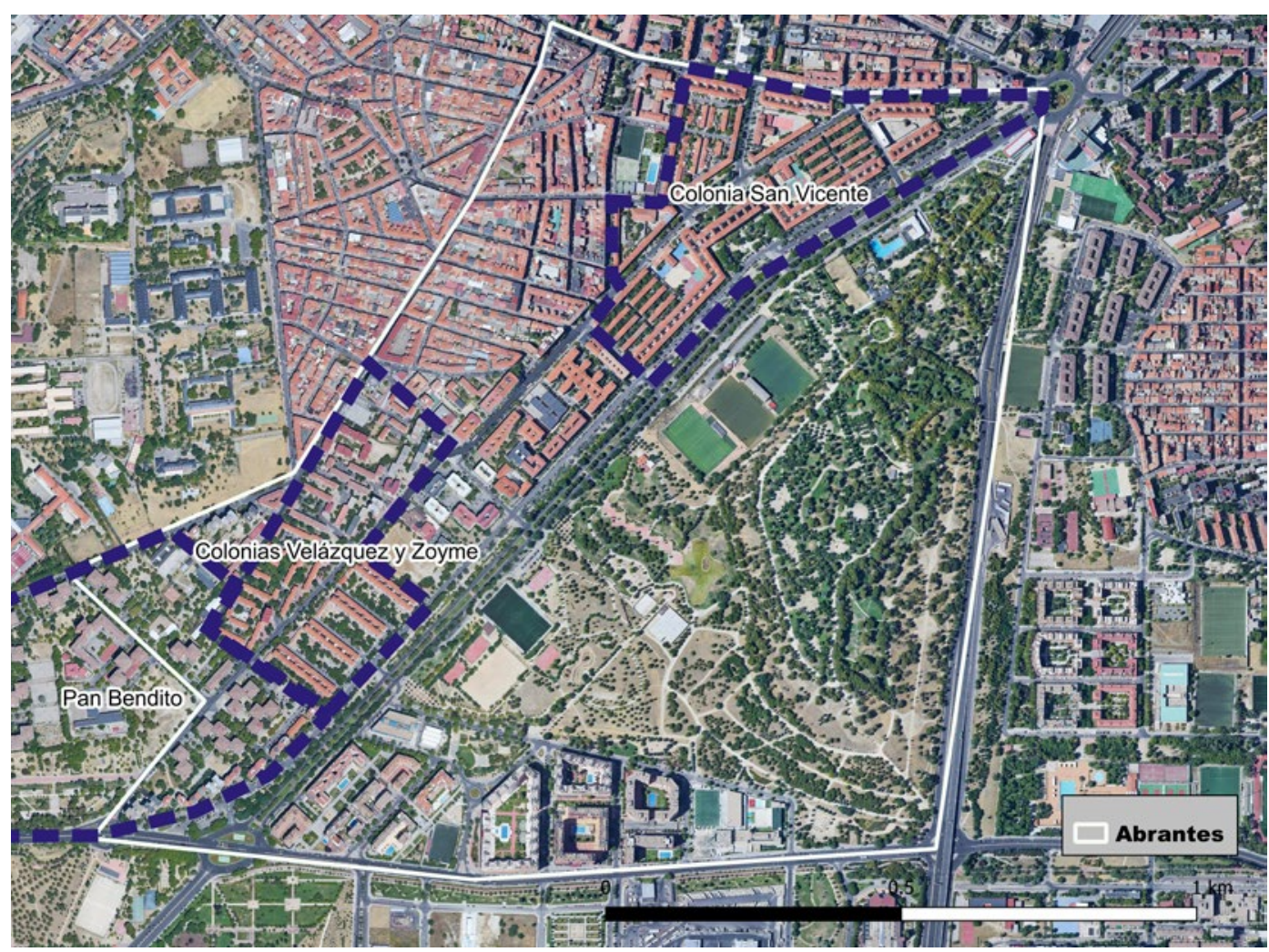

FIG. 2/ Plano de Abrantes, Carabanchel (Madrid).

urbana y rehabilitación edificatoria de la UVA de Pan Bendito en la década de 1980, dentro de la Operación de Barrios en Remodelación. Más adelante, en 1999, la Comunidad de Madrid declaró la Zona de Rehabilitación Integrada de las Colonias Velázquez y Zoyme, lo cual permitió la incorporación de ascensor en los bloques de cinco plantas y aislamiento de los edificios. Más adelante, el diseño definitivo del Plan MAD-RE (Madrid Recupera) incluyó en 2018 tres Áreas Preferentes para el Impulso a la Regeneración Urbana (APIRUs) dentro del contorno de Abrantes, abarcando casi todas las viviendas del barrio.

El origen residencial y urbanístico del barrio tiene consecuencias sobre el estado de su actual parque residencial, cuyo valor medio era notablemente inferior en 2017 al de la media de la ciudad (1.644 €/m² en Abrantes, $3.285 € / \mathrm{m}^{2}$ en Madrid, según el Índice Inmobiliario Anual de Idealista. com). Al respecto, y según los datos del Censo de 2011 (INSTITUTO NACIONAL DE EstadísticA, 2013), el estado de los edificios del barrio se encontraba levemente más deteriorado que la media de la ciudad (un $6,2 \%$ en estado mejorable, frente al 5,4\% del conjunto de la ciudad), concentrándose tales situaciones en las viviendas en edificios construidos entre 1951 y 1970 (el $8,4 \%$ del total de las viviendas entre 1951 y 1960 y el $10,3 \%$ de las viviendas entre 1961 y 1970). De manera similar, carecía de ascensor un $79,5 \%$ en las viviendas construidas en dicho período (en contraste con el $52,0 \%$ del barrio y el $33,0 \%$ de la ciudad). Finalmente, tales viviendas carecían de calefacción en un $25,8 \%$ de los casos, frente al $17,4 \%$ del barrio y el $14,4 \%$ de la ciudad. Se observa, por tanto, una clara distinción en el interior de las viviendas de Abrantes, con una concentración de los problemas residenciales en los edificios y viviendas construidas durante la etapa desarrollista del franquismo.

Al respecto, existen diferencias sociales y residenciales en el interior de Abrantes. En concreto, la zona noroeste del barrio está compuesta en más de la mitad de su parque residencial por viviendas construidas entre 1961 y 1970 . Estas viviendas, que constituyen el $35 \%$ de las viviendas del barrio, concentran buena parte de los problemas residenciales, dado que el $65 \%$ de las viviendas en edificios en estado mejorable 
y el $52,4 \%$ de las que no cuentan con ascensor se encuentran en esta área. En línea con el proceso mencionado de sustitución residencial, en 2011 un $39,6 \%$ de los habitantes de esta zona había nacido en el extranjero, a diferencia del resto del barrio, donde representan el 27,1\% (INSTITUTO NACIONAL DE EstadísticA, 2013). En este contexto, Abrantes es un ejemplo del tipo de procesos de sustitución de población nativa por personas inmigrantes extranjeras empobrecidas, las cuales ocupan los vacíos dejados por aquellos residentes que entre 2001 y 2011 pudieron moverse hacia viviendas y barrios con mejores condiciones urbanísticas y residenciales (SORANDO \& UCEDA, 2018).

Como consecuencia de todo lo anterior, en la actualidad Abrantes es un barrio relativamente joven, étnicamente diverso y empobrecido, como se observa en la FIG. 4. Su juventud relativa está ligada a la importante presencia de personas inmigrantes extranjeras $(31,1 \%$, en contraste con el $22,2 \%$ de la ciudad). Mucha de esta población ha adquirido la nacionalidad española, dado que tiene nacionalidad extranjera un $17,1 \%$ de la población. Entre los residentes de nacionalidad extranjera destaca la población procedente de América Latina $(9,8 \%$ de la población de Abrantes), Asia (2,5\%) y los países integrados en la Unión Europea a partir de 2004 $(3,1 \%)$. Por el contrario, la presencia de residentes procedentes de países de la Unión Europea con renta media mayor o de otros países de la OCDE es significativamente bajo $(1,1 \%$, frente al $2,3 \%$ de la ciudad). Vinculado a la llegada de esta población se encuentra el porcentaje de hogares con cuatro o más adultos $(9,9 \%$, frente al $7,5 \%$ en el resto de la ciudad) que, en un parque residencial de superficies inferiores a la media, da lugar a fenómenos de hacinamiento relativo. En concreto, la superficie media por habitante en Abrantes es de 28,1 metros cuadrados por habitante (33,5 en Madrid), que son 20,1 en ausencia de personas españolas, según el Censo de 2011 (INSTITUTO NACIONAL DE ESTADísTICA, 2013). Finalmente, es muy importante la concentración de población gitana en Pan Bendito, fruto de las políticas de realojo de población chabolista de los años ochenta y noventa (LA RUECA, 2018).

En cuanto al empobrecimiento relativo, la tasa de parados sobre la población de 16 a 64 era del $11,6 \%$ en Abrantes (frente al $9,4 \%$ de media en Madrid) y la renta neta media por hogar en 2015 era de $27.998 €$ (en contraste con los $38.535 €$ en Madrid). Este empobrecimiento relativo se produce entre una población con un nivel de estudios que también se encuentra por debajo de la media madrileña: en 2018 , el $17,6 \%$ de los mayores de 25 años tenía estudios superiores, a diferencia del 35,2\% en Madrid. Este perfil socioeconómico se complementa, por último, con una relativa ausencia de locales abiertos con actividad económica, dado que hay 2,2 de estos locales por cada 100 personas, frente a los 3,2 en Carabanchel y 3,3 en Madrid, según los datos de la Subdirección General de Estadística del Ayuntamiento de Madrid.

\subsection{Las Fuentes (Zaragoza)}

El barrio de Las Fuentes es un distrito localizado al este de Zaragoza. Su población es de 42.057 habitantes en 2019, según el Padrón municipal (INSTITUTO NACIONAL DE EstadísticA, 2020). Esto supone un 6,2\% del total de la ciudad, aunque este porcentaje ha ido disminuyendo en los últimos años, por la dinámica demográfica negativa de la última década. La densidad de población es de 6.681 habitantes $/ \mathrm{km}^{2}$, superior a la media de la ciudad. Este dato adquiere mayor relevancia si se tiene en cuenta que tan sólo se ha edificado una pequeña parte del distrito (EBRóPOLIS, 2017), quedando el resto para uso agrícola: la denominada "huerta de las Fuentes".

El barrio forma parte del primer cinturón obrero de la ciudad, construido entre la posguerra y las décadas desarrollistas de la dictadura (tan sólo 100 de las viviendas actuales se construyeron antes de 1940), con características similares a otros barrios que forman el tejido tradicional y consolidado de la ciudad (Delicias, San José, Torrero, etc.). Su crecimiento y desarrollo urbano respondió a una planificación escasa, en la que el objetivo principal era alojar a migrantes rurales que venían a trabajar en el sector industrial. Los planes urbanísticos posteriores configuraron una estructura urbana reticular, en manzanas rectangulares de dirección esteoeste, y de unos 180 por 50 metros, que mantienen cierta homogeneidad (AYUNTAMIENTO DE ZARAGOZA, 2017a).

El barrio cuenta con equipamientos educativos, sanitarios, deportivos y otros que fueron construidos durante los años 80 y 90 del siglo anterior durante el ciclo político socialdemócrata, atendiendo a las reivindicaciones vecinales (Alberich, 2007; TISSOT, 2013). Como ocurre en otros barrios similares de la ciudad, dos de sus calles centrales son los ejes vertebradores del comercio local. Un sector económico que se ha visto muy afectado por la instalación de centros comerciales en la periferia, algunos de ellos muy próximos geográficamente, produciéndose un vaciamiento progresivo de estos pequeños 
negocios, con la consiguiente pérdida de tránsito y actividad en muchas de sus calles (BARINGO \& GAVIRIA, 2001; GómEZ, 2013).

Demográfica y socialmente, varios procesos se suman y retroalimentan. La fotografía más amplia nos muestra una población envejecida (edad media de 46,7 años, casi 2,5 años mayor que la media de la ciudad), ligeramente feminizada (índice de masculinidad: 94'9) y de bajo nivel económico (la renta neta media anual por persona es inferior en $2.170 €$ a la media de la ciudad). El distrito cuenta también con uno de los porcentajes de población extranjera más altos $(18,1 \%)$, así como de mayores de 65 años que viven solos $(17,8 \%)$. Las áreas geográficas de procedencia más comunes son la rumana $(38,5 \%)$, seguida de las africanas $(26 \%)$ y americanas (20\%). En cuanto a nivel de estudios, el $76 \%$ de la población posee, como máximo, la Educación Secundaria Obligatoria, y la población con estudios superiores es menos de la mitad que la media de la ciudad.

De forma más concreta, el primer proceso es el de sustitución de segmentos de población joven, con mayor formación que sus ascendientes, que han abandonado progresivamente el barrio, en busca de viviendas con estándares constructivos más recientes. En su lugar, conforme las viviendas con más carencias estructurales en la edificación (ausencia de calefacción, aislamiento, garaje o ascensor) quedan vacías y la población autóctona envejece, han llegado al barrio nuevas vecinas y vecinos. Son personas con rentas bajas que proceden bien de las migraciones internacionales, bien de otros barrios y municipios, en busca de viviendas que pueden pagar. Esto ha permitido que algunas zonas del barrio, con viviendas peor dotadas, rejuvenezcan.

No obstante, los informes municipales advierten de que, al mismo tiempo, el barrio se está segregando en dos zonas, según su edad, su renta y su diversidad étnica. En la zona "noreste" (ver FIG. 3), el porcentaje de población mayor de 65 años supone un $35 \%$, y el de mayores de 80 años supera el $11 \%$, en algunas zonas censales, siendo el área donde existe un mayor porcentaje de población en hogares unipersonales: población envejecida en situación de viudedad, que por sus bajos ingresos no ha podido trasladarse a otros entornos urbanos con viviendas más adecuadas y mejor equipadas (SANZ \& al., 2007). En general, la población anciana requiere el apoyo de unos servicios sociales específicos

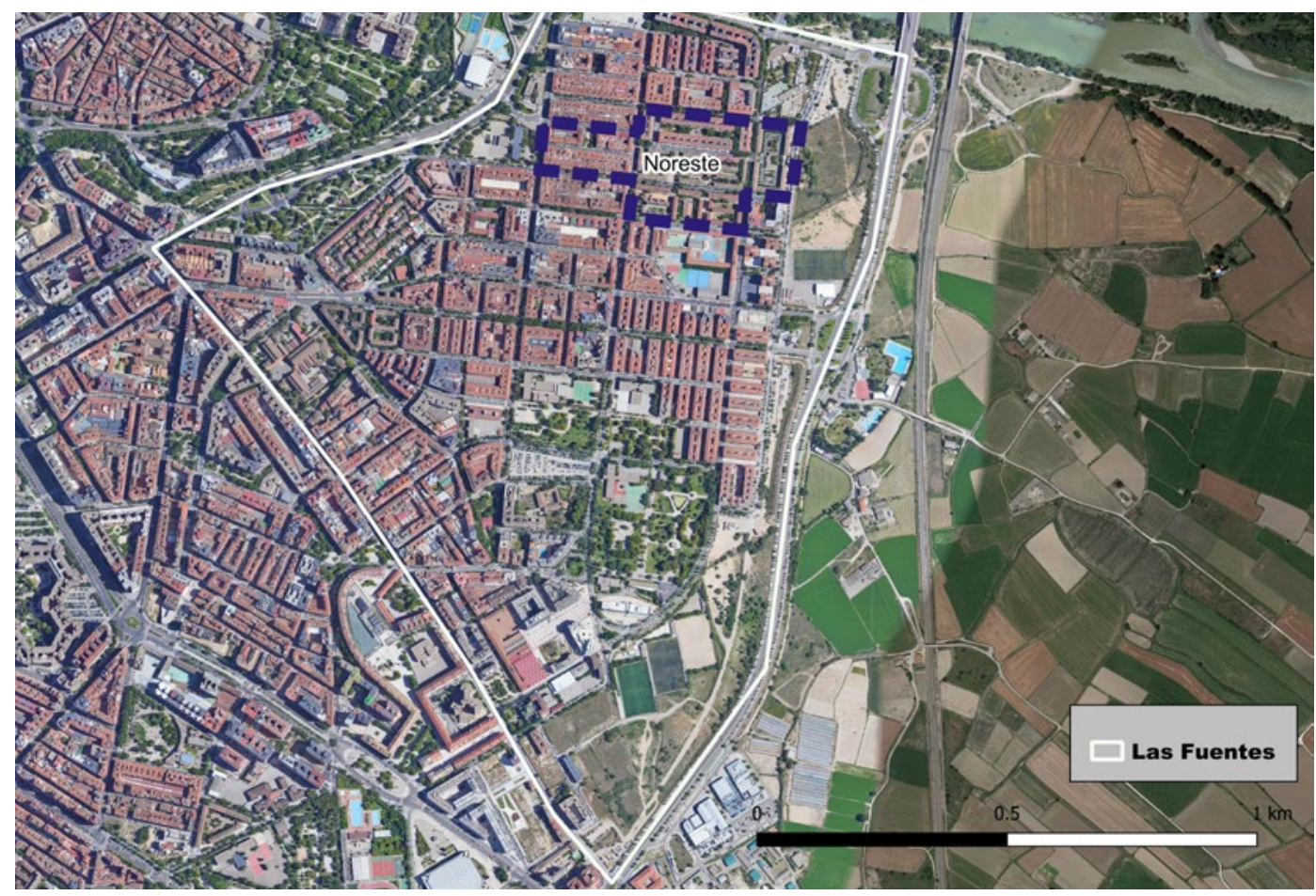

FIG. 3/ Plano de Las Fuentes (Zaragoza). 
para la realización de sus funciones diarias, y es la principal afectada por el hecho de que un $26,2 \%$ de las viviendas del barrio carezcan de ascensor. Al mismo tiempo, en esta zona hay secciones censales con un $30 \%$ de población migrante y un $20 \%$ de población en desempleo (AYUNTAMIENTO DE ZARAgOZA, 2017b).

El otro proceso, muy ligado al anterior, es el de empobrecimiento de esa misma área del barrio. En ella se concentra la mayoría de los perceptores del Ingreso Aragonés de Inserción (renta mínima) y los salarios más bajos, por lo que, desde finales de la primera década de este siglo, los diversos estudios realizados sobre el barrio señalan que cualquier proyecto de rehabilitación arquitectónica "debe de ir acompañado de una serie de medidas de integración social, para evitar la formación de guetos y de procesos de segregación" (AYUNTAMIENTO DE ZARAGOZA, 2017b: 53).

Las dinámicas sociodemográficas, por tanto, aparecen estrechamente vinculadas a las características de la vivienda. En Las Fuentes hay 19.8691 viviendas agrupadas en 1.063 edificios. En 2010 había 1.622 viviendas vacías, un 4,6\% de dicho censo, por debajo de la media de los distritos de la ciudad, en torno al $10 \%$. Un $22,0 \%$ de las viviendas no cuenta con ningún tipo de calefacción central ni individual, nueve puntos por encima de la media de la ciudad (ZARAGOZA VIVIENDA, 2017). Y el 79,1\% de las viviendas del barrio fueron construidas antes de 1980, siendo el distrito de Zaragoza con mayor porcentaje de ese tipo de viviendas. Teniendo en cuenta esto, los estudios municipales sitúan al barrio entre el parque edificado más desfavorecido en términos de eficiencia energética y acceso a calefacción (AYUNTAMIENTO DE ZARAGOZA, 2017a).

El modelo de tenencia y los precios de la vivienda también están siendo afectados por el envejecimiento demográfico y la obsolescencia arquitectónica. Por una parte, el abandono progresivo del barrio por una cohorte joven ha sacado muchas viviendas al mercado del alquiler, estando el de compra y venta muy afectado todavía por el ciclo económico que comienza con la Gran Recesión (EscolANo \& al., 2018). Estos precios, tanto de venta como de alquiler, responden a la dualidad del barrio y tienen como actores poco estudiados a los bancos (poseedores de 14 de los 21 pisos analizados en una muestra del área de Urbanismo del ayuntamiento, en 2017) y a quienes buscan en el Noreste del barrio "inversiones propicias": particulares interesados en obtener ganancias regulares, fáciles y con poco riesgo, que adquieren en esa zona viviendas a bajo coste, y cuyo objetivo es alquilarlas a terceros, combinando a menudo bajos arrendamientos con hacinamiento (AYUNTAMIENTO DE ZARAgOZA, 2017a: 25).

Hasta el momento, las actuaciones públicas de rehabilitación de edificios se han concentrado tan sólo en esa zona más antigua, en los denominados "Conjuntos Urbanos de Interés", que concentran 1200 viviendas (un 6,0\% de las del barrio), construidas entre 1954 y 1957 (RUIz \& RuBIO, 2006). Pese a estas intervenciones, el Centro Municipal de Servicios Sociales advierte de que en estas viviendas se produce un incremento continuo de solicitudes de ayuda económica, con:

"familias en situaciones muy precarias y viviendas en muy mal estado (...) en una zona cuya situación es de marginación social cronificada (...) $\mathrm{y}$, además, hay bastante movimiento de familias por viviendas ocupadas" (AYUNTAMIENTO DE ZARAGOZA, 2017b: 60).

Finalmente, en cuanto al resto de las políticas públicas sobre vivienda, estas son desarrolladas por el Ayuntamiento de la ciudad, con poca participación del gobierno autonómico (AGUERRI, 2005). No hay un peso significativo del barrio en las viviendas gestionadas por su sociedad municipal Zaragoza Vivienda: apenas un 2,64\% de las incluidas en los programas de Viviendas de Precio Reducido o del programa Zaragoza Alquila. Aunque sí se registran en Las Fuentes solicitudes para acceder a una vivienda social, situadas en otros barrios: el $17 \%$ de las solicitudes de toda la ciudad (ZARAGOZA VIVIENDA, 2017).

En resumen, la situación socioeconómica y de vivienda en ambos barrios se corresponde con la de otros territorios urbanos, afectados por la progresiva segregación de las ciudades del Sur de Europa (ARBACl, 2019). En ambos casos se observa una dualización de su espacio físico y humano, en forma de periferia interior (MATEsanz \& HERnÁndez, 2016). Ante estos procesos, los actores públicos y privados con presencia en el barrio plantean medidas propias del urbanismo "re" (GARNIER, 2016), como la "delimitación de zonas de actuación prioritaria por su especial vulnerabilidad" (ZARAGOZA VIVIENDA, 2017). En todo caso, entre ambos barrios hay también diferencias significativas que se sintetizan en la FIG. 4.

\section{Análisis de las entrevistas}

A partir del trabajo de campo cualitativo, el análisis de los discursos ofrece la siguiente categorización de los resultados: perfil de los residentes en estos dos barrios, servicios y pertenencia al 


\begin{tabular}{lccccc}
\hline Variable & Año & Abrantes & Madrid & Las Fuentes & Zaragoza \\
\hline Habitantes & 2019 & 30.748 & 3.266 .126 & 42.057 & 674.997 \\
\hline \% Niños/as (0-14) & 2019 & 15,4 & 13,3 & 11,6 & 14,1 \\
\hline \% Mayores de 65 & 2019 & 18,0 & 20,3 & 25,8 & 21,3 \\
\hline$\%$ Nacidos en el extranjero & 2019 & 31,1 & 22,2 & 16,8 & 14,1 \\
\hline \% Nacidos en África & 2019 & 1,3 & 1,5 & 4,2 & 2,9 \\
\hline \% Nacidos en América & 2019 & 23,1 & 14,4 & 7,0 & 6,4 \\
\hline$\%$ Nacidos en Asia & 2019 & 2,6 & 2,3 & 1,0 & 0,9 \\
\hline Renta media por hogar & 2015 & 27.998 & 38.535 & 25.158 & 31.382 \\
\hline Renta media alquiler $\left(€ / \mathrm{m}^{2}\right)$ & 2018 & 9,5 & 13,2 & 6,6 & 6,9 \\
\hline
\end{tabular}

FIG.4 / Características sociodemográficas de Abrantes (Madrid) y Las Fuentes (Zaragoza).

Fuente: elaboración propia a partir de los datos del INE y el MINISTERIO DE TRANSPORTES, MOVILIDAD Y AGENDA URBANA.

territorio, situación de la vivienda y estrategias y percepciones sobre las acciones públicas y privadas en torno a esta. Previamente, exponemos el marco de análisis de las políticas públicas que nos permite interpretar dichos resultados.

\subsection{Dos ciclos políticos: resultados convergentes}

La ciudad de Madrid, como Valencia y otras peninsulares, ha atravesado desde 1978 un ciclo político conservador muy vinculado al urbanismo expansivo y financiarizado (OMM, 2007; LóPEZ
\& Rodríguez, 2010; Romero \& al., 2018). Por contra, la ciudad de Zaragoza, con un modelo de gobernanza urbana empresarialista basado en grandes proyectos (BELLET \& ALONSO, 2016; DíAZ \& al., 2018), se ha desarrollado urbanística y socialmente mediante pactos entre fuerzas socialdemócratas, con tan sólo dos legislaturas conservadoras. Como mostramos en la FIG. 5, ambos modelos de gestión de las políticas urbanas tienen un impacto similar sobre los dos barrios estudiados y difieren en los modelos de movilización vecinal más recientes. Por tanto, la actual dualización en estos barrios, con la aparición de periferias interiores, supone una convergencia en los efectos actuales de tradiciones

\begin{tabular}{|c|c|c|}
\hline Ciudad & Madrid & Zaragoza \\
\hline Modelo de gestión & Conservador & Socialdemócrata \\
\hline Políticas de ciudad & Ciudad global y empresarial & $\begin{array}{l}\text { Hacia la ciudad global: localización e } \\
\text { infraestructuras }\end{array}$ \\
\hline Cohesión social & $\begin{array}{l}\text { Incremento de la desigualdad } \\
\text { socioeconómica }\end{array}$ & $\begin{array}{l}\text { Incremento de la desigualdad } \\
\text { socioeconómica }\end{array}$ \\
\hline Cohesión urbanística & $\begin{array}{l}\text { Incremento de la segregación residencial y } \\
\text { de la distancia social }\end{array}$ & $\begin{array}{l}\text { Fragmentación residencial e incremento } \\
\text { de la distancia social }\end{array}$ \\
\hline Barrio & Abrantes & Las Fuentes \\
\hline Políticas de barrio & $\begin{array}{l}\text { Planes de barrio débiles y sin política de } \\
\text { vivienda }\end{array}$ & $\begin{array}{l}\text { Rehabilitación débil y ausencia de plan } \\
\text { integral }\end{array}$ \\
\hline Efectos & Dualización y periferia interior & Dualización y periferia interior \\
\hline Activismo vecinal & $\begin{array}{l}\text { Activismo vecinal clásico frágil } \\
\text { Nuevo activismo vecinal (15M) }\end{array}$ & Activismo vecinal clásico \\
\hline
\end{tabular}


políticas aparentemente antagonistas (GIMENO \& MontAÑÉs, 2017). No obstante, ambas se basan, en gran parte, en la subordinación del gasto público a los intereses de las nuevas oligarquías empresariales locales, con una elevada transferencia de renta y patrimonio a los clústeres familiares con mayor acumulación previa de capital (OMM, 2007; A ZoFRA, 2013; VILLENA, 2019).

\subsection{Cambios sociodemográficos}

En el momento de su edificación, estos barrios obreros contaban con una relativa homogeneidad de clase social y su diversidad cultural se limitaba a la proporcionada por las migraciones intrapeninsulares, casi siempre del hábitat rural al urbano, y la presencia de núcleos de infravivienda habitada por población gitana. En el último caso, dicha vivienda se concentra en Pan Bendito, en el caso de Abrantes, pero no en Las Fuentes. Actualmente, ambos constituyen nuevos barrios: a) multiculturales, debido al reciente ciclo de migraciones internacionales hacia el Estado español; b) envejecidos, como consecuencia de la salida de los jóvenes hacia las nuevas periferias y al segundo anillo residencial (CALvo \& al., 2011; OMM, 2015); y c) con una homogeneidad de clase apenas alterada, que permite que sus habitantes lo consideren bien un "barrio obrero", bien un "barrio sin solución", según las zonas de estos barrios (GIMENO \& JIMÉNEZ, 2020).

El cambio de barrio de los jóvenes, en busca de viviendas edificadas con estándares más contemporáneos, ha contribuido, por tanto, al envejecimiento de la población autóctona. En ambos barrios, tal población pertenece a la generación que vio construir sus primeras calles (habitantes nacidos durante la posguerra). Sus viviendas no cuentan con los servicios necesarios para facilitar su vida diaria, de acuerdo con su actual edad. Asimismo, los servicios públicos desplegados como consecuencia del ciclo de movilización vecinal de la segunda restauración monárquica (ALBERICH, 2014), son inadecuados a la actual proporción de población anciana. Otra de las consecuencias de este envejecimiento es el incremento en el porcentaje de habitantes que superan los 80 años. Estos se concentran, como hemos visto ya, en determinadas viviendas, edificadas en los años del desarrollismo de la dictadura, nutriendo buena parte de los casos de viviendas habitadas por una única persona.

"Muchas de las viviendas son antiguas, de cuando el barrio empezó a crecer y se fueron yendo a vivir allí (...) Muchas otras no tienen ascensor, a día de hoy (...) Un número muy pequeño de viviendas disponen de medios para calentar la casa. En algunas viviendas no abunda la luz (...) y los baños, pues muchos tienen bañera, en lugar de ducha, el tamaño es muy reducido, etc. Entonces, pues están muy poco adaptadas para el perfil de personas que están viviendo en estos momentos en esas casas." (Enfermera, Las Fuentes).

En cuanto a la población en edad de trabajar, la salida de los jóvenes con mayor cualificación y renta ha conformado en estos barrios unos grupos con rentas bajas y cualificaciones inferiores a la media de la ciudad, sobre los que ha recaído el mayor impacto de las consecuencias de la Gran Recesión. Entre ellos se encuentran parejas jóvenes con pocos recursos, que se instalan en estos barrios por la ventaja relativa en el precio del alquiler, así como un notable número de hogares monomarentales que se enfrentan a una inabordable conciliación entre el trabajo y los cuidados, en un contexto de apoyos institucionales muy débiles.

\begin{abstract}
"Pero, ¿quién va a venir a vivir aquí? Nadie le apetece Pan Bendito para vivir, pero es verdad que hay gente que ha venido porque no tiene otra... o sea vives aquí o vives en la calle, o te vas otra vez a tu pueblo (...) A mí me encantaría irme de este barrio, pero es que no... por eso... quiero sacarme el graduado, tener un título, tener algo, y poder salir de aquí..." (Mujer joven, Abrantes).
\end{abstract}

Esas cohortes de edad son las que se forman, además, con mayor aportación de habitantes de origen extranjero, con edad media inferior al resto y un peso creciente entre las cohortes de menores de edad. En este caso, se produce por primera vez en la historia de estos barrios un proceso de segregación en el acceso a los servicios: la redistribución de la población escolar, siguiendo pautas de evitación propias de otros distritos de mayor renta media (white flight). En él se mezclan los factores de renta (real y percibida) y los étnicos (añadiéndose, en el caso de Abrantes, el estigma de la población gitana al de las personas inmigrantes extranjeras). En consecuencia, una parte de las familias autóctonas se inscribe en centros donde se percibe menor presencia de familias extranjeras (CARRASCO, 2020). Mientras que otra parte de las familias extranjeras se inscribe en centros donde se perciben mejores resultados académicos, en ambos casos incluso fuera del barrio. De este modo, las familias con menores recursos, tanto de ingresos como académicos, quedan relegadas en centros guetizados.

"Julián Besteiro era un colegio que se convirtió en una especie de sumidero, de todo lo que los 
colegios privados no querían, entonces estamos hablando de poblaciones de aluvión, inmigrantes, entonces son colegios a los que hay que dedicar grandes recursos porque están trabajando con poblaciones que a lo mejor no dominan el castellano, porque son hijos de inmigrantes que acaban de llegar etc. Etc. Y que necesitan, por ejemplo, un trabajo con ese aspecto, será un colegio en ese aspecto abandonado por parte de la administración" (Movimiento social post-15M, Abrantes).

Estos procesos de segregación en los micropublics (BERG \& al., 2019) contrastan con una percepción más proactiva respecto a la diversidad étnica y cultural en el caso de Las Fuentes. Se trata del discurso que habla de barrio migrante o acogedor como consecuencia de la superposición de dos ciclos migratorios en un mismo espacio de la ciudad: rural-urbano e internacional. De acuerdo con estos discursos, la convivencia entre habitantes de diferentes orígenes no depende de la cultura sino de la forma en la que se desarrollan las interacciones con "los otros": en clave bien de civismo (GIMÉNEZ, 2003), bien de civility (BANNISTER \& al., 2006; VERTOVEC 2007).

\footnotetext{
"Los emigrantes son la punta del iceberg, pero yo creo que el tema está más abajo. Cuando no había inmigrantes en el barrio también había dificultades. La forma de vida las ha aumentao, también. Hay distinción entre vecinos, en los mismos bloques. No por ser inmigrante. Por ser moroso, porque los críos hacen mucho ruido, porque nos molesta todo para convivir" (Grupo focal, Las Fuentes).
}

En el caso de Abrantes, la experiencia prolongada de una composición más segregada en términos étnicos, como consecuencia de la política de concentración de población gitana en Pan Bendito, da lugar a reflexiones semejantes, si bien más ásperas, de las relaciones entre payos, gitanos e inmigrantes (LA RUECA, 2018):

\footnotetext{
"Hay una pluralidad mayor, pero dice un amigo mío: "esto no es multicultural, es multi-in-cultural", porque es un reflejo que parece que no nos entendemos nadie." (Residente y participante en movimientos vecinales clásicos, Abrantes).
}

De acuerdo con estos discursos, la homogeneidad percibida es la de clase, de modo que esta emerge como una oportunidad endógena, incluso cuando también se producen prácticas de competencia por abajo (CEA, 2015), como consecuencia de los efectos del ciclo económico en curso, tanto en la Gran Recesión como en su fase actual, vinculada a la pandemia de la COVID-19. Este ciclo estimula la competencia por unos recursos escasos, mermados por una década de políticas de austeridad, así como ahonda las desigualdades entre vecinas autóctonas y migradas, tanto en renta, como en oportunidades.

"En un entorno empobrecido hay una lucha por los recursos (...) En las actividades para la infancia se hacen unas preinscripciones, se valora a las familias, y se decide qué niños y qué familias tienen menos recursos, y éstos son los que entran en la actividad (...) $Y$ hay muchos niños subsaharianos. Nos acusan, entre comillas, que sólo damos actividad a los negros. Con la evaluación en la mano, quienes menos recursos tienen son ellos" (Grupo focal, Las Fuentes).

Estas diferencias tienen también su reflejo en el espacio, tal como refleja el recurrente discurso sobre la dualidad de estos barrios. En un polo del barrio se encuentran las zonas donde las viviendas han sido rehabilitadas (a cargo de la renta de sus habitantes, ante la debilidad de las políticas públicas) o son de reciente construcción, de forma que la mayoría cuenta con ascensor y calefacción. En estas áreas se concentra, además, la mayoría del comercio y de los servicios públicos. En el polo opuesto destacan las viviendas promovidas por la dictadura militar, en las cuales predominan los edificios sin ascensor, aislamientos deficientes, etc. Estas viviendas son el lugar de residencia de familias con baja renta, de origen tanto local (incluyendo vecinas gitanas), como migrante.

"Yo vivía, por ejemplo, en una vivienda construi-
da en los años 70, en el tardofranquismo y eran
viviendas de trabajadores: fontaneros, albañiles,
pequeños funcionarios, etcétera, etcétera. Y en-
tonces, la población mayor que seguía viviendo
en estas casas, pero poco a poco sus hijos ya
no vivían en esas casas. Se fueron a las nuevas
construcciones, a otras viviendas, como una me-
jora social, ¿vale? Esa población, ¿quién fue? A
medida que esa población envejecida ha ido des-
apareciendo, ¿quién iba ocupando esos nuevos
pisos? Pues la nueva población trabajadora, bá-
sicamente, inmigrante" (Movimiento vecinal 15M,
Abrantes).

Esta dualización del territorio contribuye al refuerzo de un discurso que ya estaba presente en otras etapas del ciclo de especulación inmobiliaria. Según esta línea argumental, propia del asociacionismo vecinal clásico y otros actores afines, ciertos barrios se encuentran infradotados de infraestructuras públicas básicas, con un volumen de población migrante por encima de la media de la ciudad y necesitados de políticas urbanísticas en clave de "re": revitalización, regeneración, rehabilitación, etc. (GARNIER, 2016). Esta imagen forma parte de la retórica discursiva de problematización, cuando no de victimización, 
de los distritos del primer anillo obrero (GIMENO \& JIMÉNEZ, 2020) y se extiende, entre otros, y de manera muy destacada, al ámbito escolar.

"Este barrio, en comparación con otros barrios, es tremendamente diferente. Mucho más deprimido, a nivel económico, a nivel cultural, me refiero de cultura general" (Grupo focal, Las Fuentes).

Por último, estos cambios demográficos apenas influyen en los discursos sobre las vecinas de etnia gitana. Esta población fue realojada durante los años 90 del pasado siglo, como resultado de programas de erradicación del chabolismo. En el caso de Las Fuentes, un programa promovido por la asociación de vecinos, a través de su Fundación, distribuyó a estas familias por viviendas de casi todo el barrio. Por el contrario, y tal como se ha adelantado, en el caso de Abrantes esta población está concentrada mayoritariamente en Pan Bendito, como resultado de la política de realojo de población chabolista dentro del Programa de Remodelación de Barrios (RENES, 2008; LA RuECA, 2018). El efecto combinado de esta operación, por un lado, y el abandono de esta zona en un contexto de racismo generalizado hacia lo gitano, por el otro lado, ha consolidado un estigma muy poderoso sobre este barrio.

"Si vas a algún sitio, di que eres de Carabanchel, no digas que eres de Pan Bendito." (Mujer joven Abrantes).

En ambos casos, a estas familias se han sumado recientemente hogares desplazados desde otros barrios, como resultado del encarecimiento de sus viviendas de origen. Con ellas ha llegado al barrio de Las Fuentes, y se ha consolidado en Pan Bendito (dentro de Abrantes), un perfil de usuarios de los servicios sociales con necesidades propias del ciclo de realojo ya citado: abandono escolar, desempleo crónico, consumo o venta de sustancias adictivas, ocupación de viviendas, etc.

"Abrantes sería como la frontera con el Bronx. Estamos hablando de que (...) el Pan Bendito, perdón, se ha degradado muchísimo. Hay un fenómeno un poco extraño, a las poblaciones gitanas inicialmente que eran de realojo, la ha ido sustituyendo una población gitana todavía más empobrecida, entonces, ya, venía de países del este o venía de Extremadura o Andalucía. Hubo como una especie de elite gitana que vivía en ese barrio y lo abandonó y a su vez se ha incorporado otra. Era un barrio tradicionalmente con muchísimos problemas de drogo-pendencia, trapicheo, drogas, vuelve a haberlo." (Movimiento Social post-15M, Abrantes).

\subsection{Servicios y pertenencia al territorio}

En este apartado existen notables diferencias entre la percepción de las personas entrevistadas en uno y otro barrio. En Abrantes, las quejas sobre el estado de los servicios y equipamientos públicos, así como del comercio, es recurrente. En cambio, en Las Fuentes existe consenso sobre la disponibilidad de unos equipamientos públicos (transporte, educación, sanidad, etc.) y servicios privados (comercio, etc.) adecuados y cercanos, además de una buena posición respecto al centro de la ciudad. Ambos barrios se benefician de la proximidad a áreas verdes apreciadas por las vecinas. Asimismo, vecinas y actores colectivos señalan dos déficits específicos. Por un lado, que los recursos no están presentes con la misma intensidad en las áreas con viviendas más antiguas (en el caso de Las Fuentes) o con mayor concentración de población gitana realojada (en el caso de Abrantes). En estas zonas, además, se considera que la seguridad es menor que en el resto del barrio. Finalmente, se coincide en que los barrios carecen actualmente de fuentes locales de empleo, con el cierre progresivo de los talleres y otros centros de trabajo, que se han desplazado a nuevas periferias industriales.

\footnotetext{
"Es un barrio que está muy desatendido. No sé si habéis... si os dais una vuelta, hay rincones que están completamente sucios, desentendidos, están feos, no arreglados. Entonces, claro, así es que es difícil cambiar... (silencio) $Y$ de infraestructura es que no tiene apenas nada, o sea, la gente se va, pues o se va a Islazul que está aquí en el centro comercial, que tiene ahí al lado tiene un polideportivo, y bueno, hay alguna familia que va allí, pero muy pocas, la verdad es que las condiciones socioeconómicas de la población impiden que puedan realizar cualquier actividad que no sea el ir al parque o... vamos, o ir a... la ludoteca que está aquí al lado que es gratis o sabes... es complicado" (Directora Centro Educativo en Pan Bendito, Abrantes).
}

En cuanto al comercio, este ha sufrido el impacto del proceso de ampliación de los grandes centros comerciales, que ha sido paralelo al cierre de comercios locales desde el inicio del actual ciclo económico en 2008, jalonado por sucesivas crisis. Estos cierres se atribuyen, también, a la disminución progresiva de la renta media del barrio, vinculada con los cambios sociodemográficos ya descritos. Así como a factores ligados a las políticas de vivienda, como la ausencia de políticas de rehabilitación, que dificultan una mayor presencia en las calles a las personas mayores, que habitan los edificios sin 
ascensor. Esos mismos cambios demográficos han traído consigo también la apertura de negocios por parte de vecinas de origen migrante, así como de otros dirigidos a esta misma población. En este caso se repiten en los comerciantes de origen autóctono los discursos presentes en otros barrios multiculturales del Estado basados en estereotipos (GómEZ, 2013). Un trabajo de campo más amplio permite verificar que no hay tal segregación en los consumos, según criterios étnicos (GIMENO, 2017).

"La gente que se jubila no vuelve a abrir. Y como el poder adquisitivo en el barrio no es muy alto, tiene que haber tiendas con precios un poquico más bajos. Entonces las tiendas que tienen precios más altos, pues a la larga tienen que cerrar. Ya que muchos por motivos económicos van más a comprar a centros comerciales, a tiendas que les beneficia más." (Asociación de comerciantes, Las Fuentes).

Finalmente, en cuanto a la pertenencia al barrio, encontramos dos posiciones en ambos barrios. En Las Fuentes se da una valoración positiva de la "identidad de barrio" existente. Esto es, durante el trabajo de campo se percibe con claridad que las personas que viven en ese territorio tienen conciencia de que el mismo está diferenciado del resto de la ciudad, y de que sus habitantes se identifican unos con otros como parte de una comunidad. Por contra, también se es consciente de que existen relaciones sociales negativas, entre grupos humanos, caracterizados étnica y económicamente. Ante esta distancia social percibida, algunas de las participantes proponen la creación de espacios de encuentro, actualmente ausentes, que erosionen esa desconfianza.

"He percibido la ausencia de espacios donde podamos debatir las diferentes ideas (...) y eso lo hemos perdido en el barrio (...) Antes se hacía la Coordinadora de Problemática Social, se trabajaba conjuntamente (...), lo importante era la convivencia y la relación" (Grupo focal, Las Fuentes).

Esta falta de espacios de encuentro también se subraya en el caso de Abrantes donde la identidad territorial tiene una escala distinta al barrio: vinculada al distrito (Carabanchel) o a un sector del mismo (Pan Bendito). Junto con esta ausencia de identidad se destaca la debilidad de los lazos sociales y la distancia entre grupos según su origen migrante, con la excepción de los articulados en torno a ciertos centros religiosos como las parroquias o, sobre todo, los puntos de culto evangélico (en todo caso segregados étnicamente). Finalmente, el caso de Pan Bendito destaca por la doble cara vinculada a su estigma: por un lado, el control social de una comunidad aislada, así como la mancha del lugar que se extiende sobre sus habitantes; $y$, por el otro lado, su carácter protector en un entorno social hostil (WACQUANT, 2007).

\begin{abstract}
"Y ahora está rebotando muchísimo lo del tema del racismo... pero una barbaridad. Entonces claro, ellos se sienten también muy seguros en el barrio. Porque en el barrio te protegen y en el barrio... Tú perteneces al barrio (...) Y, al fin y al cabo, es donde te van a proteger, y donde al final siempre vuelves. Por eso es difícil salir" (Asistente al culto evangélico, Abrantes).
\end{abstract}

\subsection{Situación de la vivienda}

En cuanto a las características de la vivienda en estos barrios, hay también un consenso entre las personas entrevistadas. El envejecimiento del parque de viviendas y la expansión de la ciudad, que ha dejado estos territorios dentro de la trama urbana consolidada, constituyen dos referencias fundamentales para interpretar la situación. Estas dificultades se suman a una percepción más positiva de quienes han habitado el barrio durante más tiempo.

\begin{abstract}
"Actualmente hay una mejora importante en el barrio, o sea, es que en el barrio no teníamos ni un parque infantil en condiciones, o sea, el parque que está ahí en este descampado que habréis atravesado seguramente, ni existía, o sea, es que no había ni zonas donde los niños pudieran estar. Entonces, bueno, poco a poco se ha ido mejorando." (Directora Centro Educativo en Pan Bendito, Abrantes).
\end{abstract}

En todo caso, la dualidad urbanística y social del barrio viene dada por la generación de esas periferias interiores (KÁPSTEIN, 2010). La ausencia total o parcial de regulación urbana durante el periodo especulativo del desarrollismo franquista ha causado la aparición de estas áreas vulneradas en el interior de los barrios obreros tradicionales: la zona norte de Las Fuentes, por un lado; y Pan Bendito (como resultado de las políticas de realojo y su intenso abandono urbanístico y social) e importantes sectores del resto de Abrantes (debido a las características deficientes de sus viviendas y edificios) por el otro lado, áreas más o menos vivibles hasta que, tras otro periodo de acumulación capitalista a través de la especulación urbanística, se traspasa el "umbral desencadenante" o momento crítiCo (RENES, 2015; Gimeno \& MontAÑÉs, 2017).

"Las dos zonas (...) se diferencian también por el tipo de vivienda. En ellas se puede encontrar, como en todos los barrios, pues un poco de todo 
(...) La zona de Las Fuentes norte, la gran mayoría de los edificios son edificios antiguos (...) Y, sin embargo, en la parte de Torre Ramona es una zona de nueva construcción y que sigue creciendo. Entonces, no tiene mucho que ver una zona con la otra. En el barrio hay una zona mucho más deteriorada, que siempre es motivo de reivindicación vecinal" (Enfermera, Las Fuentes).

Este proceso de periferización de una parte de los barrios incide también en los precios de la vivienda, tanto en la compra como en el alquiler. Sobre este último también hay consenso en que, tratándose de viviendas no acordes a los estándares de edificación actuales, los precios son "demasiado altos" y se han incrementado durante los últimos años. Esta consecuencia de procesos de especulación inmobiliaria supralocales, sólo se percibe en el trabajo de campo por el efecto de la subida en los precios, pero las participantes no la vinculan a ninguna causa concreta en el caso de Las Fuentes. En cambio, en Abrantes se observa un enmarcado crítico de estos procesos, fundamentalmente promovido por el tejido asociativo posterior al 15M.

"Es imposible, piden ahora fianza, te piden nóminas, te piden aval, 700 euros, una vivienda de dos habitaciones... están ahora mismo, ahora mismo para mi es imposible que una persona o una familia que tenga un trabajo pueda adquirir una vivienda. Es increíblemente caro" (Mujer inmigrante y madre sola, Abrantes).

En Abrantes, esta situación conlleva una muy intensa ocupación de viviendas vacías por parte de la población con menos recursos económicos, con frecuencia expuestas a mafias intermediarias. En tales contextos, protagonizados por personas migrantes de origen extranjero, hogares monomarentales y población gitana, ni siquiera el hacinamiento es una estrategia viable para hacer frente al pago del alquiler, especialmente entre aquellos hogares sin familia extensa con quien ir a vivir.

"Hay un montón de gente que coge por internet y está viviendo de okupa porque legalmente no puede acceder, o sea, tiene que entrar a las mafias estas que están alquilando" (Mujer migrante extranjera y madre sola, Abrantes).

El progresivo deterioro de la vivienda conlleva nuevas afecciones a la calidad de vida de las habitantes de los edificios más obsoletos. En el ámbito de la salud, esta percepción es común entre habitantes y profesionales, debido a los impactos que dicho deterioro tiene sobre la salud física y mental: a la ya mencionada soledad de las personas con movilidad reducida se unen el malestar emocional y el estrés provocados por la precariedad económica (UBRICH, 2019).
"El ascensor no funciona, bueno, pensar... entonces claro, para nosotros esa población que es tan vulnerable, que no puede salir de casa, que se cronifica, precisamente, las enfermedades aumentan... se cronifica muchísimo más por las barreas arquitectónicas. Es una población muy vulnerable... y hay mucha población, muchas mujeres mayores... son todo mujeres mayores que viven solas" (Trabajadora Social, Abrantes).

\subsection{Políticas de vivienda}

Durante el trabajo de campo hemos constatado importantes diferencias entre los dos casos de estudio. En el caso de Abrantes, las políticas de vivienda son continuamente mencionadas por su ausencia y el abandono del sistema de provisión residencial al mercado. En cambio, en el caso de Las Fuentes se observa la intervención de dos conglomerados de actores en este ámbito: por una parte, las diferentes administraciones públicas (estatal, autonómica y local); y, por otra parte, entidades privadas, vinculadas mayoritariamente a los servicios sociales asistenciales. Al respecto, las participantes señalan que el deterioro del parque de vivienda se debe a la falta de una intervención urbanística global. La intervención pública ha desplegado su acción con recursos económicos insuficientes y sobre áreas concretas de los barrios, no sobre el conjunto de estos. Incluso en la época de bonanza o expansión económica, la intervención pública no ha sido suficientemente significativa para evitar el actual envejecimiento de los edificios y la población. Esta dinámica se ha mantenido, con menos recursos aún, durante la aplicación de las políticas de austeridad durante la última década.

"La administración tiene recursos, cuando quiere tiene capacidad coercitiva, lo vemos constantemente en nuestro alrededor, sin embargo, no ponen toda esa capacidad coercitiva al servicio de las necesidades de las personas (...) entonces por ejemplo con la Comunidad Autónoma de Madrid, la reclamación y la exigencia es "vendisteis vuestras viviendas sociales" (Movimiento social post-15M, Abrantes).

Esta ausencia de una priorización de la inversión pública en el ámbito de la vivienda responde a un modelo de ciudad expansiva, en el que la población y las inversiones privadas circulan por el territorio y el tiempo, extrayendo beneficios de esa configuración de la ciudad como mercado. A este modelo extractivo se oponen unas políticas que priorizan la rehabilitación y la vivienda pública como garantía de acceso universal a la vivienda (DEL PINO \& al., 2016). En esta oposición entre modelos de políticas, el último entramado 
de propuestas proviene del ciclo político del municipalismo socialdemócrata. En el caso de Madrid, es relevante la llegada al gobierno municipal de Ahora Madrid, impulsor del programa Madrid Recupera (MAD-RE), cuyos efectos en Abrantes todavía no son evaluados por las personas entrevistadas. Asimismo, existe consenso en torno al incremento de las inversiones urbanísticas y sociales en Abrantes (alrededor de los Planes de Barrio) mientras duró esta excepción de cuatro años al hegemónico gobierno neoliberal del municipio y la Comunidad de Madrid (en este segundo caso inalterado). No obstante, estas mejoras no se extendieron al ámbito de la vivienda pública, atrapada en el discurso y la práctica de la austeridad.

"Nosotros en Pan Bendito llevamos ejecutando unos contratos públicos dentro del plan de Barrios... y los hicimos hasta al año 2015 (...) Llegó un momento que lo único que primaba en la contratación pública era la baja económica, nosotros perdimos ese contrato porque no bajamos donde se suponía que había que bajar, la entidad que cogió ese contrato, que no recuerdo quien era, duró 6 meses. Cuando ellos se fueron, el barrio se quedó prácticamente sin nada, el nivel de conflictividad aumentó, el nivel de suciedad aumentó, el nivel de precariedad aumentó, coincidió cuando ya llegó el nuevo gobierno municipal... sí que poco a poco está volviendo a inyectar recursos en el barrio y sí que poco a poco se están notando leves mejorías" (Organización del Tercer Sector, Abrantes).

En el caso de Zaragoza, el barrio estudiado ha sido destinatario de un Plan de Barrio. Al contrario que los Planes Integrales existentes en el mismo municipio desde los años noventa (EscolANO \& al., 2018), los últimos en diseñarse no cuentan con partidas presupuestarias específicas. Por lo que quedan como contenedor sin contenido, en cuanto a capacidad de revertir el proceso actual de deterioro urbanístico y de condiciones de vida. Este último episodio en las políticas urbanísticas locales se suma a los ya iniciados en ciclos políticos anteriores, durante los últimos treinta años (LEÓN \& CARPINTERO, 2018; MONCLÚS \& BAMBÓ, 2018). Para las participantes, la principal percepción es que, dado que esas actuaciones no han sobrepasado la etapa de diagnóstico y se han centrado a menudo en las áreas más degradadas urbanísticamente, poseen un error intrínseco de diseño: su verticalidad, en tanto no cuentan con el conocimiento de los habitantes y otros profesionales del territorio. Contribuyen así a una percepción pesimista respecto a la capacidad y/o voluntad de quienes gestionan estas políticas, así como a una sospecha respecto a la redistribución de los presupuestos de acuerdo con criterios ajenos a los diagnosticados, recelo que es compartido en Abrantes.

"En Las Fuentes tenemos un plan de barrio, el primer documento que tenemos es una suma de cosas, hemos analizado situaciones. Pues tenemos dos zonas en el barrio, una más desfavorecida que otra. Entonces tenemos muchos datos, ahora hay que analizarlos y ver dónde priorizamos. Hemos sido de los barrios más estudiados. La cuestión importante es la voluntad política, que va en función de los presupuestos. Lamentablemente, el nuevo gobierno [conglomerado conservador y extrema derecha] ha disminuido un poco los recursos para los barrios. Lo hemos notado. Tenemos dinero ahorrado para algún programa, que vamos a llevar a cabo con los parques, etc. Pero, ahora mismo, les dan más prioridad a otros barrios como la Romareda, etc., que a las Fuentes." (Asociación Vecinal, Las Fuentes).

En el caso de Zaragoza emergen dudas sobre la adecuación para las rentas más bajas de las débiles propuestas de rehabilitación implementadas hasta ahora, siempre centradas en las zonas más deterioradas. De la misma forma se cuestiona su capacidad para revertir los procesos en marcha.
"Las condiciones que había antes no son las que hay ahora. Pues la legislación ha cambiado, y nos encontramos con cosas que están impidiendo que avancemos en la rehabilitación de las viviendas. Por ejemplo, ahora se desgrava en la renta, y en algunos casos eso les supone perder el IAI o la RAI [subsidios asistenciales] (...) El problema es que, si desgrava a los vecinos (...) están en el lími- te de la renta, y ahí les desbarata todo y la gente no se atreve." (Asociación Vecinal, Las Fuentes).

La menor incidencia de las políticas públicas en lo arquitectónico contrasta con un papel más marcado de las acciones asistenciales de las administraciones locales desde sus áreas de vivienda. En el caso de Las Fuentes, las unidades familiares que reciben apoyo desde Zaragoza Vivienda tienen también apoyos en otras entidades públicas y privadas (renta mínima, subsidio de desempleo, etc.) por presentar necesidades más allá del alojamiento. Como resultado hay una concurrencia de profesionales y programas que abordan estas necesidades, a veces con dificultades para coordinarse, ante la carencia de un enfoque comunitario en sus intervenciones (ASOCIACIÓN VECINAL LAS FUENTES, 2004). Este problema también se observa en Abrantes, donde concurren actuaciones intermitentes y fragmentadas cuya función es la contención de algunas necesidades sociales urgentes, nunca la transformación de sus condiciones de 
posibilidad. Esta dinámica se complementa con el descrédito y la desconfianza hacia las instituciones públicas (tanto en su dimensión social como policial) por parte de una población que manifiesta no esperar nada de las mismas.

"Hemos tenido, eh... unos años que no ha habido, o sea, que esto era un desierto de... o sea, muy pocas fundaciones e instituciones estuvieron trabajando y, además, era como una manera de... de... muy desconexionada, o sea, había como trabajo... mmm... por separado de los... entonces nos hemos sentido solas durante muchos años (...) Entonces, bueno, poco a poco se ha ido mejorando, es verdad que se ha invertido mucho en subvencionar instituciones que trabajan con población... en exclusión." (Directora Centro Educativo en Pan Bendito, Abrantes).

Al mismo tiempo, esta carencia de medios suficientes provoca que las zonas más deterioradas de los barrios sean las más accesibles para realojar a familias procedentes de otros distritos y ciudades, así como de asentamientos chabolistas, tal como ocurrió en Pan Bendito. Este efecto de concentración espacial de personas en situación precaria es señalado tanto por actores asociativos como por profesionales de los servicios sociales.

"Tenemos un Casco Histórico, con un Plan Integral potentísimo, que ha supuesto que una parte, que era La Magdalena, se convirtiera en una especie de barrio de Gracia en Barcelona (...). Entonces, qué pasa, pues que toda esta gente que estaba en vivienda barata en La Magdalena, se viene al barrio de Las Fuentes, donde la vivienda es muy barata (...) porque estamos al lado." (Trabajador social, Las Fuentes).

Este ámbito del Estado del Bienestar ha concertado o contratado muchos de sus programas con entidades privadas con y sin ánimo de lucro. Entre estas últimas, las entidades privadas prestadoras de servicios sociales asistenciales proveen de recursos no vinculados directamente a la vivienda (alimentación, apoyo a madres solas, búsqueda de empleo, etc.). Estas entidades también son conocedoras de necesidades de alojamiento en las que intervienen muy puntualmente a través de ayudas urgentes (p.e. pago de recibos de alquiler o de suministros de energía).

\subsection{Estrategias vecinales}

En ausencia de políticas públicas de vivienda capaces de revertir el deterioro urbanístico y social de los territorios estudiados, sus habitantes han desplegado diversas estrategias colectivas de autodefensa. Al respecto, el movimiento vecinal clásico de ambos barrios ha seguido una evolución semejante desde la reivindicación política a la gestión de servicios financiados por instituciones públicos y/o privadas. De tal modo, su actividad política durante las últimas décadas del siglo $\mathrm{XX}$ ha resultado fundamentalmente cooptada y desactivada (ALBERICH, 2007). Al respecto, en Abrantes se recuerda el hito del Plan de Desarrollo Comunitario en Pan Bendito, durante la década de los noventa, como contraste de la actual desmovilización de un tejido asociativo frágil, tan sólo parcialmente revitalizado tras la ola del $15 \mathrm{M}$. Esta última movilización apenas se ha manifestado en el caso de Las Fuentes, donde la Fundación El Tranvía representa un ejemplo claro de despolitización, dependencia de los recursos externos (sin los cuales se descarta el trabajo sobre cualquier cuestión) y, por tanto, una dependencia cada vez mayor de la nueva filantropía (con La Caixa como actor relevante en ambos barrios).

\footnotetext{
"Valoran lo que en un momento dado se hizo, si no, no te saludarían, no se pararían contigo a contarte cómo les va (...). Sí percibo estancamiento... hay momentos de boom (...) y también por lo que sea se para, o se corta (...) digo eso porque digo "Jo, podía haber cambiado hace tanto tiempo... cuando se pensaba en comunidades, y que la gente participara y que no hiciera falta agentes de fuera, profesionales para que la vida de un barrio tuviera un otro... otro tono..." $Y$ yo eso, no lo veo" (Residente participante en Plan Comunitario).
}

En este contexto, desde algunas asociaciones clásicas se responsabiliza a los residentes de su falta de participación, si bien el discurso mayoritario alude a las dificultades para el compromiso colectivo desde posiciones sociales extremadamente precarizadas, reiteradamente definidas en torno a la lucha diaria por la supervivencia:

\footnotetext{
"Quien está excluido no participa. Pues no va a las AMPAS, no va a votar, no va a las reuniones de la comunidad, no va a nada. La exclusión es ausencia de participación (...) De donde vienen, ¡los conceptos de participación son tan distintos!" (Grupo focal, Las Fuentes).
}

En la búsqueda de recursos para satisfacer las necesidades sociales más básicas, los grupos sociales más precarizados necesitan unas redes de apoyo mutuo que se encuentran muy debilitadas. Además, carecen de apoyos institucionales suficientes, no conocen a las asociaciones clásicas y de los movimientos sociales políticamente activos (vinculados al $15 \mathrm{M}$ en el caso de Abrantes) obtienen soluciones temporales. En este entorno sociopolítico, nuevos actores colectivos están asumiendo la función social no cubierta por el Estado. Entre ellos destaca 
el caso de las iglesias evangélicas, con gran ascendente sobre las poblaciones gitana y latinoamericana (si bien a través de puntos segregados). Estas iglesias sustituyen las funciones sociales que no cumple el Estado, entre las cuales destaca la promoción de la salud (prevención del consumo de drogas, de la emergente ludopatía y el maltrato). Asimismo, se trata de espacios fundamentales de identidad y reconocimiento en una sociedad hostil, así como lugares centrales de relación social que, en cambio, son con frecuencia excluidos por las entidades del tercer sector por su carácter religioso.

"La labor social que están haciendo los del Punto [evangélico], pues ahora mismo lo están haciendo ellos, no lo está haciendo nadie más (...) Por eso tanto gitano se está convirtiendo al Evangelio, porque ellos piensan... La gente se piensa que es algo meramente religioso y yo creo que no es solamente religioso. Es comunitario." (Asistente al culto evangélico, Abrantes).

\section{Conclusiones e implicaciones para las políticas públicas}

Esta investigación se planteaba el reto de aproximarse a los efectos del abandono de las políticas públicas, tanto de rehabilitación de la vivienda, como de promoción del acceso a la misma, sobre los perfiles más precarizados por la Gran Recesión que habitan dos barrios multiculturales de clases populares en Madrid y Zaragoza.

En primer lugar, concluimos que la trayectoria sociodemográfica de este tipo de barrios está fundamentalmente condicionada por la ausencia de políticas de vivienda capaces de revertir la inadecuación de los edificios y las viviendas en peores condiciones. En plena incorporación del caso español al proceso de financiarización de la vivienda, tal ausencia dio lugar a la salida de la población autóctona más joven y cualificada hacia nuevos desarrollos inmobiliarios con mejores condiciones residenciales. En su lugar, nuevos habitantes, muy a menudo migrantes, han reemplazado a quienes dejaron las viviendas en peor estado, a las cuales acceden dado que son aquellas con precios de alquiler asequibles para sus bajas rentas. Junto con estos nuevos habitantes permanece la población más envejecida, para la cual son particularmente graves las carencias ligadas a estas viviendas (ausencia de ascensor, calefacción, etc.), tanto en términos sanitarios como relacionales.

En segundo lugar, concluimos que los discursos sobre el cambio de barrio obrero a barrio pobre
(GIMENO \& JIMÉNEZ, 2020) dan cuenta de la incapacidad de un porcentaje creciente de habitantes para afrontar las mejoras necesarias en sus viviendas. La profunda precarización de los residentes de estos barrios no encuentra respuesta en las instituciones públicas, cada vez más retraídas en acciones asistenciales y de control, sin efecto redistributivo ni capacidad de embridar a un mercado inmobiliario al cual, por el contrario, promueve. En este contexto, las instituciones son objeto de un progresivo descrédito que deja espacio para la emergencia de nuevos actores colectivos con una influencia creciente sobre los habitantes más precarizados (como las iglesias evangélicas, notablemente).

En tercer lugar, y por todo ello, se evidencia la consolidación de periferias interiores donde el mercado concentra a los grupos más precarizados en las viviendas más inadecuadas. En estos territorios se reproducen dinámicas sociales y habitacionales propias de décadas precedentes (chabolismo vertical, ocupación de viviendas, absentismo escolar, etc.), cuando el Estado del bienestar todavía no había desarrollado unas políticas redistributivas, posteriormente fragilizadas bajo el paraguas neoliberal de la austeridad.

En cuarto lugar, estos factores condicionan las estrategias de los habitantes más precarizados tanto para acceder a la vivienda como para mejorar su situación socioeconómica. Al respecto, se observan diferencias entre Abrantes y Las Fuentes fundamentalmente vinculadas a sus contextos políticos locales, tanto institucionales como asociativos. En Madrid el ciclo es profundamente neoliberal y convierte a su área metropolitana en un laboratorio de la mercantilización de la vida social, destacadamente en el caso de la vivienda y el suelo. En cambio, en Zaragoza se observa un ciclo socialdemócrata con efectos sobre los barrios en términos de equipamientos y políticas de rehabilitación. El resultado son puntos de partida distintos que explican, en parte, diferentes tejidos asociativos: desde la emergencia de movimientos vecinales en la estela del $15 \mathrm{M}$ en los barrios periféricos y abandonados de Madrid; hasta su ausencia generalizada en la periferia zaragozana, donde sólo permanecen movimientos vecinales clásicos, en declive y despolitizados.

Finalmente, ambos territorios comparten la consolidación del ámbito asistencial compuesto por entidades, fundaciones y movimientos vecinales al servicio del sector público $\mathrm{y}$, más recientemente, de la nueva filantropía. El fortalecimiento de este ámbito es compatible con el ataque a los vínculos sociales que comporta el proyecto neoliberal en su despliegue de las políticas 
de austeridad durante la segunda década del siglo XXI. Por tanto, se observa una convergencia en la reperiferización de los barrios estudiados, ante la cual resultan impotentes las propuestas de intervención socio-urbanística sin partidas presupuestarias y políticas estructurales que las respalden, por mucho que cuenten con el apoyo del ámbito académico y técnico. El modelo actual de progresivo abandono de algunos territorios catalogados como vulnerables por los conglomerados beneficiados por la globalización económica apenas puede ir más allá del paradigma del desarrollo comunitario. En la fase actual de precarización económica generalizada, las herramientas asistenciales y de promoción de la convivencia, como respuesta a la inversión de sentido de la movilidad social (ahora descendente) y a la diversificación étnica de la población, son insuficientes para satisfacer las necesidades sociales en estos territorios (GiMeno, 2018).

Sin embargo, las políticas públicas y los actores colectivos presentes en el territorio no han explorado todavía las posibilidades que transcienden los paradigmas anteriores. Más allá de dichos planteamientos hay cabida para establecer alianzas que incluyan la superación de las desigualdades cuando se aborda la agenda de las políticas de vivienda (TALPIN, 2018). Para ello, los académicos y los técnicos que elaboran diagnósticos y propuestas pueden favorecer esta alternativa capacitando a los habitantes del territorio para liderar estos procesos (GARNIER, 2016). Al respecto, la profundización en la democracia debe ser parte central de los procesos de priorización de las medidas que desarrollan las políticas públicas. Este aspecto exige el acompañamiento de las acciones urbanísticas (incluidas nuestras investigaciones) con las herramientas adecuadas para favorecer una participación real de los habitantes, en la cual no sólo respondan a nuestras cuestiones, sino que, sobre todo, planteen las preguntas. Se trata de uno de nuestros retos pendientes, en el que habremos de contar con algunos de los nuevos actores colectivos en estos territorios.

\section{Bibliografía}

AguerRI, P. (2005): La vivienda y estado de bienestar en Europa. Acciones e Investigaciones Sociales, 21, 59-76.

Alberich, T. (2007): Contradicciones y evolución de movimientos sociales en España. Documentación social, 145, 183-210.

- (2014): Movimientos sociales, responsabilidad corporativa e inclusión social en la globalización. Revista Internacional de Sociología, 72, 113-132.
Alonso, L. E. (2007): "Sujetos y Discurso: el lugar de la entrevista abierta en las prácticas de la sociología cualitativa". En J. M. DELGADo \& J. M. GutiÉRREZ (Coord.). Métodos y técnicas cualitativas de investigación en Ciencias Sociales (pp. 225-240). Madrid: Editorial Síntesis.

ANDERSSON R. \& MUSTERD S. (2005): "Social mix and social perspectives in post-war housing estates". En R. VAN KEMPEN, K. DEKKER, S. HALL \& I. TOSICS (Eds.) Restructuring large housing estates in Europe (pp. 127-147). Bristol: Policy Press.

ARBACI, S. (2019): Paradoxes of segregation: Housing systems, welfare regimes and ethnic residential change in Southern European cities, Londres, John Wiley \& Sons.

Asociación Vecinal Las Fuentes (2004): "Las Fuentes: por una renovación participativa y sostenible". En Grau, E., \& Ibarra, P. (Eds.): La red en la calle: ¿Cambios en la cultura de movilización? (pp. 204-213), Barcelona, Icaria.

Ayuntamiento De Zaragoza (2017a): Programa de actuación en el Barrio de Las Fuentes, Zaragoza, Dirección de Servicios de Planificación y Diseño Urbano.

- (2017b): Aportación de Servicios Sociales Comunitarios al Plan del Barrio de Las Fuentes, Zaragoza, Área de Derechos Sociales Servicios Sociales Comunitarios.

AzofRA (2013): De la euforia del ladrillo a la crisis. Zaragoza, puesta a producir en el último ciclo capitalista, Zaragoza, A Zofra.

BANNISTER, J. \& Fyfe, N. \& KeARns, A. (2006): Respectable or Respectful? (In)civility and the city. Urban Studies, 43 (5/6), 919-937.

BARINGO, D. \& GAVIRIA, M. (2001): Pequeño comercio y vitalidad urbana en Zaragoza. La ciudad contra la anti-ciudad. Revista Catalana de Sociología, 14, 185-190.

Bellet, C. \& Alonso, P. (2016): Proyectos urbanos incompletos. Vacíos urbanos en la Zaragoza post-ave. Boletín de la Asociación de Geógrafos Españoles, 70, 285-304.

BeRg, M. L. \& GidLeY, B. \& Krausova, A. (2019): Welfare micropublics and inequality: urban superdiversity in a time of austerity. Ethnic and Racial Studies, 42 (15), 2723-2742.

BETRÁN, R. (2002): De aquellos barros, estos lodos: la política de vivienda en la España franquista y postfranquista. Acciones e investigaciones sociales, 16, 25-67.

- (2005): Sobre vivienda, urbanismo y ciudad. Acciones e Investigaciones Sociales, 21, 5-58.

Calvo, J. L. \& PueYo, Á. \& ZúÑIGa, M. (2011): La ciudad de Zaragoza en un escenario de crisis: diagnóstico y propuestas territoriales para nuevos paradigmas urbanos. Geographicalia, 59-60, 47-59.

CARRASCO, S. (2020): "Aspiraciones y oportunidades desde la equidad educativa local: de la investigación sobre el abandono escolar prematuro a la intervención sobre el terreno". En D. GARCíA \&, C. GIMENO \& B. Dieste \& A.C. Blasco (Eds.). Políticas públicas frente a la exclusión educativa. (pp. 69-74). Zaragoza: Prensas Universidad de Zaragoza.

CEA, M. A. (2015): Los efectos de la crisis económica en la molduración y evolución de la opinión pública española ante la inmigración. Migraciones, 37, 29-52. 
CoRTÉs, L. (2008): "Nuevos y viejos problemas residenciales: Vivienda y exclusión". En C. BELLET; J. GANAUY J. M. LLOP (Eds.), Vivienda y sociedad: nuevas demandas, nuevos instrumentos (pp. 57-72). Lleida, Milenio.

DEL PINO, E. \& Rubio, M. J., \& AdELANTADO, J. (2016): Los estados de bienestar en la encrucijada: políticas sociales en perspectiva comparada, Madrid, Tecnos.

DESMOND, M. (2012): Disposable ties and the urban poor. American Journal of Sociology, 117 (5), $1295-1335$

DíEz, A. (2015): La vivienda social como patrimonio urbano: análisis de la patrimonialización de tres Barrios de Promoción Oficial madrileños. Tesis doctoral. Universidad Politécnica de Madrid. Disponible en: http://oa.upm.es/39877/

DíAZ, F. \& LourÉs, M. L. \& MARTíneZ, I. (2018) Zaragoza: Retrato de una ciudad en transición. Working Paper Series Contested Cities.

Ebrópolis (2017): Plan de Barrio. Las Fuentes. Elementos para el diagnóstico, Zaragoza, Ebrópolis.

Escolano, S. \& López, C. \& Pueyo, Á. (2018): Urbanismo neoliberal y fragmentación urbana: el caso de Zaragoza (España) en los primeros quince años del siglo XXI. EURE, 44 (132), 185-212.

FERNÁNDEZ, A. (2003): La política de vivienda en España durante el franquismo. Ciudad y Territorio Estudios Territoriales, 138, 639-653.

FERNÁNDEZ, M. (2007): Vallecas, identidades compartidas, identidades enfrentadas: La ciudad, el pueblo y el campo, el suburbio y el barrio. Disparidades. Revista de Antropología, 62 (1), 33-83.

GARcía, C. (2015): La obsolescencia de las tipologías de vivienda de los polígonos residenciales construidos entre 1950 y 1976 . Desajustes con la realidad sociocultural contemporánea. Informes de la Construcción, 67 (Extra-1), 1-9.

GARNIER, J.P. (2016): Un sociólogo urbano a contracorriente, Barcelona, Icaria.

GıMÉnEZ, C. (2003): Pluralismo, multiculturalismo e interculturalidad. Educación y futuro, 8, 11-20.

GimENO, C. (2017): Comercio y convivencia en un barrio multicultural de clases populares. Abaco, 94, 64-70.

- (2018): Convivència i nous processos comunitaris al barri de San Pablo. En A. Moncusí, F. Torres y H. Fioravanti (coord.). Barris i ciutats en clau pluricultural (pp. 271-289). València: Neopatria.

— \& MONTAÑÉS, M. (2017): Planificación y desigualdad en la ciudad neoliberal: geografías de las clases populares. En A. Serrano (eds.) Políticas públicas y sociales: globalización, desigualdad y nuevas insurgencias (pp. 69-86). Zaragoza: Prensas Universitarias de Zaragoza.

— \& JIMÉNEZ, D. (2020): Intervención comunitaria en barrios populares: tensiones entre actores sociales. Trabajo Social Global, 10(18), 3-22. DOI: https://dx.doi.org/10.30827/tsg-gsw.v10i18.9415

GómEZ, P. (2013): Sociabilidad, comercio e inmigración en los barrios de Madrid. Abaco, 75, 63-68.

HeRRERA-PINEDA, I. \& IBÁÑEZ-GIJÓN, J. (2016): Intercambio y sociabilidad en las redes de ayuda mutua del barrio madrileño de La Ventilla. REIS, 154, 21-44.

HOUSING EUROPE (2019): The State of Housing in the EU 2019. Decoding the new housing reality. Consultado el 20 de junio en: https://www.housingeurope.eu/file/860/download
INSTITUTO NACIONAL DE ESTAdíSTICA (12 de diciembre, 2013): Censo de Población y Viviendas 2011. Datos detallados. https://shorturl.at/quvCF

- (enero, 2020): Estadística del Padrón Continuo a 1 de enero de 2019. Datos por secciones censales. https://shorturl.at/kmuCG

JøRGENSEN, M. \& PHILLIPS, L. J. (2002): Discourse analysis as theory and method, Londres, Sage.

KÁPSTEIN, P. (2010): Vulnerabilidad y periferia interior. Cuadernos de investigación urbanística, 71, 7-114.

LA RueCA (2018): Diagnosis Participada Abrantes (Carabanchel). Consultado el 20 de junio en: http://serviciodeconvivencia.es/el-diagnostico-participado-de-abrantes-ya-esta-disponible/

LEAL, J. (2005): La política de vivienda en España. Documentación social, 138, 63-80.

LEÓN, J. \& CARPINTERO, G. (2018): Mapa de Riesgo Social de Zaragoza. Una visión alternativa a los análisis urbanísticos de vulnerabilidad urbana. Ciudad y Territorio, 50 (197), 503-516.

LóPEZ, I. \& RodríGuez, E. (2010): Fin de ciclo: financiarización, territorio y sociedad de propietarios en la onda larga del capitalismo hispano (1959-2010), Madrid, Traficantes de Sueños.

MARCUSE, P. \& VAN KEMPEN, R. (2000): Globalizing Cities: A New Spatial Order? Malden, Blackwell.

MARTín-CrIADO, E. (2012): El fraude del capital social. Consideraciones críticas en torno a "E Pluribus Unum". Revista Española de Sociología, 17, 109-118.

MATESANZ, Á., \& HeRnández, A. (2016): La rehabilitación urbana como integración en la ciudad: Modelo de análisis desde la experiencia española. REVISTARQUIS, 5(2). DOI:10.15517/ra.v5i2.27138

MoncLús. J. \& BAMBÓ, R. (Eds.) (2018): Regeneración urbana (V). Propuestas para el barrio de Las Fuentes, Zaragoza, Sociedad Municipal Zaragoza Vivienda.

NEL.LO, O. (2004): "¿Cambio de siglo, cambio de ciclo? Las grandes ciudades españolas en el umbral del siglo XXI" Ciudad y Territorio. Estudios Territoriales, 36 (141-142), 523-542.

Observatorio METROPOlitano de MADRID - OMM (2007): Madrid, ¿la suma de todos?: globalización, territorio, desigualdad, Madrid, Traficantes de Sueños.

- (2015): "Viejas y nuevas periferias en la ciudad neoliberal: seguridad y desigualdad social". En García, S. y Ávila, D. (Coord.), Enclaves de riesgo: gobierno neoliberal, desigualdad y control social (pp. 127-162), Madrid, Traficantes de Sueños.

PAREJA-EASTAWAY, M. \& al. (2003): Large housing estates in Spain: Overview of developments and problems in Madrid and Barcelona, Utrecht: Utrecht University.

RENES, V. (2008): "Las remodelaciones de los barrios de Madrid: memoria de una lucha vecinal". En PÉREZ, V. \& SÁncheZ, P. (Eds.): Memoria ciudadana y movimiento vecinal. Madrid 1968-2008 (pp. 148-171), Madrid, Los Libros de la Catarata.

- (2015): La trascripción del empobrecimiento general. Los barrios como el sumidero de los desechos de la crisis. Papeles de relaciones ecosociales y cambio global, 130, 89-102.

REVILLA, J.C. \& MARTíN, M.P. \& DE CASTRO, C. (2017): The reconstruction of resilience as a social and 
collective phenomenon: poverty and coping capacity during the economic crisis, European Societies, 20 (1), 89-110.

Romero, J. \& BRANDIS, D. \& MeLo, C. (2015): El giro neoliberal de las políticas para la ciudad en España. Balance a partir de los ejemplos de Madrid y Valencia. Boletín de la Asociación de Geógrafos Españoles, 69, 369-386.

RuIz, L. G. \& RuBIO, J. (2006): Nuevas propuestas de rehabilitación urbana en Zaragoza. Estudio de Conjuntos Urbanos de Interés, Zaragoza. Sociedad Municipal Zaragoza Vivienda.

SAMBRICIO, C. (Ed.) (2004): Un siglo de vivienda social. 1903-2003, Madrid, Ayuntamiento de Madrid, Ministerio de Fomento y CES.

SANZ, Á. \& Gómez, J. D., \& ZARRAlangA, A. (2007): Las Fuentes: un barrio con futuro. Diagnóstico sociourbanístico del barrio y propuesta para construir el "Barrio soñado del 2025", Zaragoza, Sociedad Municipal de Rehabilitación Urbana de Zaragoza.

SKIFTER, H. (2003): Urban sores: on the interaction between segregation, urban decay and deprived neighborhoods, Aldershot, Ashgate,

SORANDO, D., \& UCEDA, P. (2018): Fragmentos urbanos después de la burbuja inmobiliaria: el caso de Madrid. OBETS. Revista de Ciencias Sociales, 13(1): 383-410.
https://doi.org/10.14198/OBETS2018.13.1.14

TALPIN, J. (2018): Quand le community organizing arrive en France. Revue Projet, 363 (2), 29-37.

Tissot, S. (2013): Y a-t-il un "problème des quartiers sensibles"? Retour sur une catégorie d'action publique. Revista de Antropología Social, 22, 137-53.

UBRICH, T. (2019): La Vivienda, clave para la Salud. Documentación Social, 2, 1-8.

UCEDA, P. \& SoRANDo, D., \& LeAL, J. (2018): "The Diversity of Trajectories of Large Housing Estates in Madrid, Spain". En Hess, D., TAMMARU, T. y VAN HAM, M. (Eds.): Housing Estates in Europe: Poverty, Ethnic Segregation and Policy Challenges (pp. 241-262), Dordrecht, Springer Open.

Vertovec, S. (2007): New complexities of cohesion in Britain: super-diversity, transnationalism and civil integration, Londres, Department for Communities and Local Government.

VILLENA, A. (2019): Las redes de poder en España. Élites e intereses contra la democracia, Barcelona, Roca.

WACQUANT, L. (2007): Los condenados de la ciudad. Gueto, periferias y estado, Buenos Aires, Siglo XXI.

ZARAgoza VIVIENDA (2017): Planes de barrio. Propuestas desde Zaragoza Vivienda para Las Fuentes, Zaragoza, Sociedad Municipal Zaragoza Vivienda. 